\title{
The Train of Thought and Strategy of Chinese School Physical Education to Cultivate Unique Minority Students' Motor Quotient in Yunnan
}

\author{
Xuanjin Zhu1, Li Bao ${ }^{2,3}{ }^{*}$, Hangping Wang1,4, Ningyuan Zhao ${ }^{5}$ \\ ${ }^{1}$ Yunnan Normal University, Kunming, China \\ ${ }^{2}$ Nanjing University of Chinese Medicine, Taizhou Campus, Taizhou, China \\ ${ }^{3}$ Hanlin College of Nanjing University of Chinese Medicine, Taizhou, China \\ ${ }^{4}$ National Altitude Training Experimental Center (Yunnan Normal University), Kunming, China \\ ${ }^{5}$ Wuhan Physical Education Institute, Wuhan, China. \\ Email: ^2507648480@qq.com
}

How to cite this paper: Zhu, X. J., Bao, L., Wang, H. P., \& Zhao, N. Y. (2021). The Train of Thought and Strategy of Chinese School Physical Education to Cultivate Unique Minority Students' Motor Quotient in Yunnan. Advances in Physical Education, 11, 481-488. https://doi.org/10.4236/ape.2021.114039

Received: September 30, 2021

Accepted: November 26, 2021

Published: November 29, 2021

Copyright (c) 2021 by author(s) and Scientific Research Publishing Inc. This work is licensed under the Creative Commons Attribution International License (CC BY 4.0).

http://creativecommons.org/licenses/by/4.0/

\section{Open Access}

\begin{abstract}
Yunnan is one of the most typical regions of ethnic cultural diversity in China. There are more than 15 unique ethnic minorities living in Yunnan for generations. To awaken the Motor Quotient of Yunnan minority students is a subject that should not be ignored in the reform of Yunnan school physical education. At the same time, the research of Motor Quotient of Yunnan minority students is of great significance to the physical education work of Yunnan schools. The Motor Quotient training of Yunnan minority students in school physical education should start with solving the outstanding problems of Yunnan minority students in school physical education, take the Motor Quotient theory as the breakthrough point, and take the curriculum standard as the basis to cultivate the Core sports literacy of Yunnan minority students. By cultivating physical education teachers with high Motor Quotient team, the construction of system of physical education curriculum, make with characteristic of ethnic sports activities, will move Motor Quotient and the integration of sports wisdom, build the campus sports culture with unique ethnic minorities in Yunnan characteristics such as strategy, develop unique ethnic minority areas in Yunnan students Motor Quotient, enhance Yunnan unique minority students physical health, Exercise the conscious consciousness and behavior habits of Yunnan minority students, and promote their all-round development.
\end{abstract}

\section{Keywords}

Motor Quotient, School Physical Education, Yunnan Has Unique Minority 


\section{Introduction}

"MQ" is the Motor Quotient, which refers to the physical exercise ability, athletic talent level and the ability to exert athletic potential after an individual overcomes itself and objective things (Wang \& Zhang, 2014). The birth of Motor Quotient is based on the inspiration of foreign scholars on the theory of Multiple Intelligence (Allred, 1949), Bodily Kinesthetic Intelligence (Gardner, 1985), Sports Quotient, and other studies (McCloy, 1934). Motor Quotient is an important support for people's all-round development, and it, together with IQ and EQ, constitutes people's basic intelligence quality (Figure 1). In the process of human growth, only the combination and development of Motor Quotient, EQ and IQ can maximize individual value. Teenagers are the future and hope of national development, and their physical health is related to the success or failure of the development of socialist cause. It is an urgent problem to raise the adolescents' physical health to a strategic height and effectively restrain the decline of adolescents' health level.

The Third Plenary Session of the $18^{\text {th }}$ CPC Central Committee through "Decision of the CPC Central Committee on Major Issues Concerning Comprehensively Deepening Reform" in put forward "strengthen the physical education and extracurricular exercise, promote the physical and mental health of teenagers" of the call, the call reflects the era for the development of sports, the country's attention to the youth physical exercise and the improvement of the nation's physical fitness. It also strengthens the confidence and determination to carry out the investigation and research on the theory and practice of Motor Quotient. Motor Quotient plays a very important role and significance in improving the physical and mental quality of teenagers and developing their sports potential.

There are 15 unique ethnic minorities living in Yunnan province of China. Due to the cultural differences, these unique minorities have formed a special development mode combining modernity and nationality. In the context of

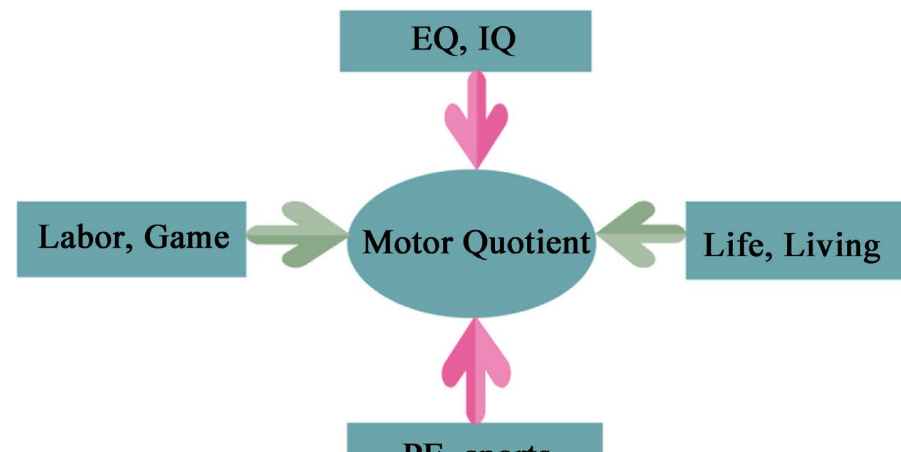

PE, sports

Figure 1. Conceptual diagram of motor quotient. 
"Healthy China 2030", how to organically combine ethnic and modern, how to take effective measures to awaken the unique minority students' Motor Quotient in Yunnan, It has become an important research content for our social workers to promote national unity, promote the school sports reform in Yunnan, promote the physical health problems of students in Yunnan minority areas, exercise the self-consciousness and behavior habits of Yunnan minority students, and promote the overall development of students.

\section{The Basic Idea of School Physical Education to Cultivate Unique Minority Students' Motor Quotient in Yunnan}

\subsection{To Solve the Prominent Problems of Yunnan Unique Minority Students in School Physical Education as the Starting Point}

In recent years, under the social atmosphere of seeking quick success and instant benefits and the pressure of entering college, the tendency of emphasizing intellectual education over physical education is prominent. Physical education has been regarded as a non-major discipline, and school physical education has been in a marginal area of education for a long time. Some Yunnan's schools arbitrarily change the teaching plan, arbitrarily reduce physical education teaching hours; there are also some schools on the schedule of physical education class can not be guaranteed, often moved to Chinese, math, English and other main subjects of remedial courses; some schools even canceled physical education classes in their graduating grades. As a result, Yunnan minority students' physical exercise time can not be guaranteed, and their physical and mental health has declined, and problems such as myopia and scoliosis are also very prominent.

The teaching of physical education is very mechanized and lacks innovative mode and thinking. The traditional PE teaching management mode is deeply rooted, and the teaching method of "herding sheep" is still prevalent. Most rural schools do not combine the physical education classroom teaching of the actual situation of the school, blindly emphasize unity, standardization and order, but ignore the unique ethnic minority students in Yunnan individual differences, ethnic differences and interests. Traditional ethnic sports is an important part of the development history of Chinese sports, but at present, the development form of ethnic sports in primary and secondary schools is relatively simple, unable to let more students realize the cultural value of ethnic sports, so that students feel boring, resulting in low level of Motor Quotient.

The physical education hardware facilities are poor, the site and teaching equipment are limited, which brings inconvenience to the development of good physical education. Yunnan belongs to the less developed provinces in western China, many schools have weak infrastructure, and the development of school sports is greatly restricted. Most rural schools only have simple sports equipment, the rate of common sports equipment is not high, traditional sports equipment still occupy a certain proportion. Some school sports equipment manage- 
ment is not good, some schools commonly used sports equipment is incomplete, the court, track damage and long-term disrepair, the only equipment left unused for a long time, resulting in loss or damage. In addition, the school extracurricular activities commonly used sports equipment shortage, gymnasium, gymnastics room and other facilities are basic.

Lack of physical education teachers, and physical education teachers in short supply. The regional development of physical education in schools is unbalanced. Many rural schools in Yunnan lack regular physical education teachers, and some teachers of other courses substitute for physical education. The quality and quantity of physical education teachers in eastern coastal areas are obviously better than those in rural schools in Yunnan, showing obvious regional imbalance. In recent years, the number of young physical education teachers in Yunnan has been increasing year by year, but their moral and professional qualities have not reached the corresponding level. Some young physical education teachers lack of dedication, no guarantee of school work hours, no progress of the curriculum, teaching without a plan.

The above outstanding problems in the teaching of school physical education to the unique minority students in Yunnan need to be solved one by one. This is the starting point of the reform of school physical education, as well as the introduction of the concept of Motor Quotient into school physical education and the training of Yunnan's unique ethnic minority students' Motor Quotient.

\subsection{With the Motor Quotient Theory as the Breakthrough Point, Improve the Unique Ethnic Minorities in Yunnan Motor Quotient Level}

According to the research of Professor Zongping Wang et al., following the theory that the narrow sense of Motor Quotient contains three elements, it is believed that the narrow sense of Motor Quotient includes three aspects: sports quality, sports psychology and physical function. The Motor Quotient is determined by factors such as heredity, acquired environment, learning and education. Innate genetic difference, different people have different levels of Motor Quotient. Some people with higher level of motor quotient are more likely to become athletes; people with lower levels of activity-quotient may experience limitations in normal life activities. The acquired environmental influence, learning and education can also affect a person's level of Motor Quotient. People with uncoordinated body and poor flexibility can improve their level of Motor Quotient through sports, making their body more coordinated and flexible.

To improve the level of Motor Quotient is to improve the ability of individuals to overcome their own and objective things to carry out sports, and to improve the ability of individuals to explore and play sports talent and potential (Tang, Zhu, \& Jiang, 2021). Therefore, to fully understand the Motor Quotient theory, deeply understand the basic concept of the Motor Quotient theory, take this as the entry point, rely on the platform of school physical education, introduce the Motor Quotient theory, strengthen the influence of sports culture, can 
increase the enthusiasm and initiative of students to learn physical education and health courses, can promote the school physical education reform in Yunnan. It can promote the physical health problems of students in Yunnan minority areas, exercise the self-consciousness and behavior habits of Yunnan minority students, and promote the all-round development of students, so as to achieve the goal of lifelong physical education.

\subsection{On the Basis of Curriculum Standards, Cultivate the Core Physical Literacy of Unique Minority Students in Yunnan}

The curriculum of basic education plays an important role in moral education. The $19^{\text {th }}$ National Congress of the Communist Party of China clearly stated that "we must fully implement the Party's education policy, implement the fundamental task of establishing moral integrity and cultivating talents, develop quality-oriented education, promote educational equity, and train socialist builders and successors who are morally, intellectually, physically and aesthetically welldeveloped". The new curriculum standard clearly put forward to develop students' core physical literacy, including sports ability, sports morality, healthy behavior. The revision of "PE and Health curriculum standard" is the embodiment of national will in PE teaching. School physical education in physical education teaching activities and teaching exploration and practice about Motor Quotient training for based on the curriculum standard, curriculum nature and the basic concepts, culture characteristic of minority students in Yunnan, and sports core literacy, exercise of Yunnan minority students self-consciousness and unique behavior, real purpose to promote students' all-round development.

\section{Strategies of Chinese School Physical Education to Cultivate Unique Minority Students' Motor Quotient in Yunnan}

School physical education plays a decisive role in Motor Quotient of minority students in Yunnan. The formation of Motor Quotient is the result of environment, education, culture and other factors. The teachers, curriculum, activities and campus sports culture in school sports play an imperceptible role on the unique minority students in Yunnan, which is a long-term and systematic project.

\subsection{Train a Team of PE Teachers with High Motor Quotient}

Teachers are the backbone of school physical education construction and development. A strong team of teachers is the necessary condition for the prosperity of school physical education. Yunnan province has carried out the training plan for ten thousand principals, the national training plan and other plans to improve physical education teachers and teaching level in Yunnan Province. Strengthen the training of physical education teachers, increase the ideological and moral education and Motor Quotient training, cultivate a team of sports teachers with high Motor Quotient. Only strong and high Motor Quotient's PE teachers can introduce the Motor Quotient theory into the PE class and support 
a complete PE teaching system that runs through the Motor Quotient concept.

First, actively guide in the thoughts, we regularly organize lectures related to ideological and moral education, to help teachers improve the ideological and moral level, in-depth grasp the status and role of PE teachers' work, so that they love the labor, teachers and professional dedication, do the "four good teachers", and the ideological and political education has always been throughout their sports classroom teaching. Secondly, in the aspect of Motor Quotient training, professors, experts and scholars in this field should be hired to guide physical education teachers so that they can learn Motor Quotient theory, clearly define the concept of Motor Quotient, gradually establish the awareness of spreading Motor Quotient theory, and correctly understand the importance of training students Motor Quotient. Teachers are the guiders of students' growth and the direct constructors of physical education teaching. But at present, most of the PE teachers do not know enough about Motor Quotient and lack the awareness to spread Motor Quotient to students. The level of Motor Quotient of teachers has an important influence on the level of Motor Quotient of students. It is very important to strengthen the training of Motor Quotient consciousness of teachers.

\subsection{Build Systematic Physical Education Courses and Create Sports Activities with National Characteristics}

The Motor Quotient of students is mainly based on school sports, and sports teaching is the main body of school sports, so sports courses are the basis and key to cultivating students' Motor Quotient. Physical education curriculum has its own particularity, it is limited to the venue equipment, weather environment and other external factors; there are different practical problems in every district and even every school, which need to be solved by school leaders and PE teachers. Physical education courses need systematic learning, to avoid all learning is not "skimming water" type of situation, to strive for close connection of teaching content, learning depth, and to ensure that students can learn a new motor skill every time they learn it. Therefore, physical education teaching should break through the traditional thinking, take full account of students' learning needs, and build a systematic curriculum that students love and are beneficial to students' lifelong physical development.

The teaching of physical education should pay attention to the difference and nationality of students. Physical education teachers should correctly grasp the relationship between traditional sports and modern sports, take into account the development of traditional national sports while developing competitive sports, and constantly improve the social adaptability of traditional national sports. It is of practical significance to excavate, analyze, protect and inherit the traditional sports culture and sports value of Yunnan unique ethnic minorities, such as Torch Festival, "Beating Spinning Top", "Euphorbia Royleana" and so on. The teachers should strengthen the Yunnan traditional minority national sports activities of collecting and cataloguing work, and make unique minority students 
in Yunnan understand behind the traditional sports culture and metaphor, suitable for sports activities of folk sports to reorganize and promotion, improve the traditional sports of modern social adaptability, dare to innovation, change the old teaching idea, increase the enthusiasm of Yunnan minority students to participate in sports activities with their own ethnic characteristics, and improve the level of physical health while learning the knowledge of their own ethnic culture.

\subsection{Integration of Motor Quotient Concept and Wisdom Sports}

Motor Quotient concept and Wisdom Sports can improve the organic fusion of Yunnan ethnic minorities traditional sports special adaptation in modern society, solve the Yunnan endemic when on the development of traditional minority national sports venues, equipment, the problem such as teachers' limited reserves, the physical education teaching from oneness, boring, to respect the differences of unique minority students in Yunnan, nationality, make PE teaching more interesting, diversified transition. Physical education teachers can work out personalized teaching plans based on the ethnic characteristics and interests of minority students in Yunnan, take students as the main body of the class, and better stimulate students' consciousness and enthusiasm in participating in sports activities (Zhao, Wan, \& Ma, 2020). The integration of Motor Quotient and Smart Sports can better improve students' Motor Quotient level, make the physical education class and traditional sports culture of unique ethnic minorities in Yunnan better adapt to modern society, and has positive significance for the realization of sports power.

\subsection{Create Campus Sports Culture with Unique Ethnic Minority Characteristics in Yunnan}

The construction of campus sports culture with unique minority characteristics in Yunnan has a subtle influence on the training of students' Motor Quotient. Traditional sports of ethnic minorities in Yunnan are characterized by locality, uniqueness, nationality and appreciation (Wang \& Yu, 2019). Each school should develop campus sports culture with ethnic characteristics according to its own specific situation and form its own unique school culture (Xu \& Lv, 2010). The school can set up a research group, integrate the existing sports culture resources, dig and sort out the traditional sports of Yunnan's unique ethnic minorities, strengthen the propaganda of Yunnan's unique ethnic minorities' traditional sports culture, and carry out extra-curricular sports activities with ethnic characteristics. Create a strong campus ethnic culture atmosphere, consciously spread the theory of Motor Quotient to students, make students immersed in the campus ethnic sports culture atmosphere, increase the enthusiasm of students to participate in physical education and sports activities, improve the level of Motor Quotient of students, is conducive to the formation of school characteristic culture. At the same time, it also promotes the knowledge and understanding of the excellent traditional culture of the minority students in Yunnan and en- 
hances their cultural confidence.

\section{Conflicts of Interest}

The authors declare no conflicts of interest regarding the publication of this paper.

\section{References}

Allred, P. A. (1949). An Investigation of the Predictive Possibilities of the Motor Quotient in Relation to Specific Motor Achievement of Junior High School Boys. Los Angeles, The University of Southern California, 45-46.

Gardner, H. (1985). Frames of Mind: The Theory of Multiple Intelligences. Basic Books.

McCloy, G. H. (1934). The Measurement of General Motor Capacity and General Motor Ability. Physical Education and Recreation, 5, 46-61. https://doi.org/10.1080/23267402.1934.10761657

Tang, X. E., Zhu, Y., \& Jiang, Y. Q. (2021). The Basic Thoughts and Strategies of Cultivating Students' Motor Quotient in School Physical Education. Bulletin of Sports Science and Technology Literature, 29, 46-47+58.

Wang, Z. P., \& Zhang, Y. (2014). Motor Quotient: An Important Support for Human AllRound Development. Journal of Physical Education, 21, 13-16.

Wang, S. F., \& Yu, Z. K. (2019). Ethnic Minority Traditional Sports Help the Reform and Innovation of Physical Education in Yunnan Local Universities. Sports Science and Technology, 40, 76-77+79.

$\mathrm{Xu}$, C. H., \& Lv, Y. (2010). Study on the Construction of Campus Sports Culture with Characteristics of Minority Sports Culture in Yunnan Province. Sports Science and Technology Literature Bulletin, 18, 115-116.

Zhao, D. D., Wan, B. B., \& Ma, Y. Y. (2020). Research on the Integration of Motor Quotient Concept and Smart Sports. Journal of Nanjing University of Science and Technology (Social Science Edition), 33, 46-49. 